\section{Glucocorticoid withdrawal in lupus - to do or not to do?}

I read with great interest, the recently published article in your journal titled "Withdrawal of low-dose prednisone in SLE patients with a clinically quiescent disease for more than 1 year: a randomised clinical trial" by Mathian et al. ${ }^{1}$ The discussion on the feasibility of completely stopping glucocorticoids in systemic lupus erythematosus (SLE) has been ongoing and it poses a practical challenge to every physician treating SLE. Besides the adverse effects, studies also suggest that long term glucocorticoid therapy for remission maintenance in SLE leads to increased accrual of organ damage. ${ }^{2}$ The effect of withdrawal of glucocorticoids on SLE remission has been studied in a number of observational studies. Data from a randomised trial was lacking except for a small pilot study (SIMPL) conducted by Galbraith et al where the effect of glucocorticoid withdrawal on lupus nephritis remission maintenance was studied in 15 patients. ${ }^{3}$

The above-mentioned study by Mathian et al (CORTICOLUP study) provides scientific evidence addressing this issue. The study has successfully shown the superiority of glucocorticoid maintenance therapy over its withdrawal both in terms of all flares and severe flares. ${ }^{1}$ The follow-up period was only 52 weeks, yet the number of flares in the withdrawal group were quite high $(27 \%$ vs $7 \%)$ with a HR of 0.2 . The results of the CORTICOLUP study are in contrast to the results of previous studies. $^{34}$

Majority of the patients in the CORTICOLUP study in either groups (28 and 25 in maintenance and withdrawal groups, respectively) were not on any immunosuppressive therapy besides hydroxychloroquine, and 11 patients were not on hydroxychloroquine. ${ }^{1}$ It would be interesting to know if there was any difference in the flare rates among those who were on immunosuppression compared with others. Another avenue to explore is the time of steroid withdrawal. A retrospective study by Tani et al suggests that the time interval from the last flare to the steroid withdrawal may also play a role in future flares. ${ }^{5}$ Interestingly, the quiescent time was more in the withdrawal group in CORTICOLUP study, although not significant. ${ }^{1}$

Research is ongoing to study the steroid sparing effects of biologics in remission induction. Belimumab, epratuzumab, and tabalumab have been successfully shown to reduce the steroid doses by $25 \%$ or more in remission induction in a metanalysis by Oon et al. ${ }^{6}$ The use of biologics and other immunosuppressants as steroid sparing therapy for remission maintenance in SLE is yet to be explored. In the absence of randomised trials favouring steroid withdrawal, the question remains - to withdraw or not to withdraw?

\section{Nupoor Acharya $\odot$}

Correspondence to Dr Nupoor Acharya, Internal Medicine, Post Graduate Institute of Medical Education and Research, Chandigarh 160012, India; nupooracharya88@gmail.com

Contributors NA; study design, data collection, writing.

Funding The authors have not declared a specific grant for this research from any funding agency in the public, commercial or not-for-profit sectors.

Competing interests None declared.

Patient and public involvement Patients and/or the public were not involved in the design, or conduct, or reporting, or dissemination plans of this research.

Patient consent for publication Not required.

Provenance and peer review Not commissioned; internally peer reviewed.

(C) Author(s) (or their employer(s)) 2020. No commercial re-use. See rights and permissions. Published by BMJ.

\section{A) Check for updates}

To cite Acharya N. Ann Rheum Dis Epub ahead of print: [please include Day Month Year]. doi:10.1136/annrheumdis-2020-217261

Received 29 February 2020

Accepted 3 March 2020

Ann Rheum Dis 2020;0:1. doi:10.1136/annrheumdis-2020-217261

ORCID iD

Nupoor Acharya http://orcid.org/0000-0002-2651-0864

\section{REFERENCES}

1 Mathian A, Pha M, Haroche J, et al. Withdrawal of low-dose prednisone in SLE patients with a clinically quiescent disease for more than 1 year: a randomised clinical trial. Ann Rheum Dis 2020;79:339-46.

2 Apostolopoulos D, Morand EF. It hasn't gone away: the problem of glucocorticoid use in lupus remains. Rheumatology 2017;56:i114-22.

3 Galbraith L, Manns B, Hemmelgarn B, et al. The steroids in the maintenance of remission of proliferative lupus nephritis (SIMPL) pilot trial. Can J Kidney Health Dis 2014;1:30.

4 Moroni G, Gallelli B, Quaglini S, et al. Withdrawal of therapy in patients with proliferative lupus nephritis: long-term follow-up. Nephrol Dial Transplant 2006;21:1541-8.

5 Tani C, Elefante E, Signorini V, et al. Glucocorticoid withdrawal in systemic lupus erythematosus: are remission and low disease activity reliable starting points for stopping treatment? A real-life experience. RMD Open 2019;5:e000916.

6 Oon S, Huq M, Godfrey T, et al. Systematic review, and meta-analysis of steroid-sparing effect, of biologic agents in randomized, placebo-controlled phase 3 trials for systemic lupus erythematosus. Semin Arthritis Rheum 2018;48:221-39. 